\title{
Developmental changes in sensitivity to the content, formal, and affective dimensions of paintings
}

\author{
JANE L. KENNEY and CALVIN F. NODINE \\ Temple University, Philadelphia, Pennsylvania 19122
}

\begin{abstract}
The ability of children, adolescents, and adults to analyze the content, formal, and affective dimensions of paintings was determined by asking subjects to describe similarities and differences between paintings. Content or subject matter was an important criterion of similarity for all subjects but was most salient for the preoperational aged children. Content can be regarded as the surface structure of the painting because its perception involves a direct correspondence between physical objects and events and their pictorial representations. Older children, adolescents, and adults operating at higher levels of cognitive development mentioned similarities in formal qualities such as line, shape, style, etc., and in affective or emotional qualities more often than did the younger children. Formal and affective dimensions can be regarded as the deep structure of the painting, since the perception of these elements requires the understanding that paintings also represent ideas, feelings, and experiences about reality.
\end{abstract}

At what age do children begin to become analytical about their visual perceptions? According to Gibson (1970), infants quickly learn to discriminate objects and persons in their environment. The discrimination of written symbols such as letters develops later, around the age of 5 years. When are children able to analyze more complex visual symbols, such as works of art?

The present study was designed to investigate developmental changes in children's ability to analyze paintings. Paintings have been analyzed by artists and art historians along several dimensions. Knobler (1967) describes visual art as a representation of perceptual reality, an organization of formal elements, and an expression of the emotions and subjective experiences of the artist. Using Knobler's classification as a basis, we analyzed paintings into content, formal, and affective dimensions. The content dimension of representational paintings refers to the real-world objects and events depicted in the art work. The formal dimension refers to the structural elements and relationships used in the composition of the art work. Structural elements include such qualities as line, texture, shape, and color that the

This article evolved from a study that was done by the first author to fulfill the research apprenticeship requirement for the doctoral degree. The authors would like to extend their thanks and appreciation to Patty Williams and Marla Shoemaker, art educators at the Philadelphia Museum of Art, and to Ruth Fine of the Alverthorpe Gallery in Jenkintown, Pennsylvania, for their valuable assistance in the planning and design of the study. The authors would also like to thank Tessa Lamont and Antonia D'Onofrio for their help in rating the subjects' responses. Correspondence concerning this article should be sent to Jane $L$. Kenney, Department of Educational Psychology, Sixth Floor, Ritter Annex, Temple University, Philadelphia, Pennsylvania 19122. artist uses to represent reality (Dondis, 1976). The affective dimension refers to the expressive aspects of the painting, or the feelings or mood that the artist is trying to convey.

The content of a painting is usually the most salient dimension and can be regarded as the surface structure of the art work. The perception of content requires an understanding that physical objects and events can be represented pictorially. This relationship between paintings as pictorial representations and the real-world objects to which they refer is an example of a type of correspondence rule that children learn to master during the preoperational stage of development.

The formal and affective dimensions can be regarded as the deep structure of the painting because they involve more abstract relationships between the real world and the represented world than does the correspondence rule involved in the perception of content. The perception of the formal and affective qualities of an art work requires the understanding that a painting does more than reflect physical reality. Artists use paintings to communicate their ideas about the nature of reality. In order to recognize paintings as reflections of the artist's feelings and experiences, as well as representations of physical objects and events, the viewer must be able to map onto these pictorial representations of content such abstractions as ideas, feelings, and experiences. This mapping involves the attainment of complex transformation rules relating the surface to the deep structure of the painting. If this analysis is correct, then the perception of the deep structure of the painting would require an operational level of thought.

The present study examined age differences in the viewer's ability to go beyond an analysis of surface 
structure that focuses on pictorial content to an analysis of deep structure that focuses on the formal and affective dimensions of the painting and whether these age differences can be related to cognitive development. Our view is that aesthetic appreciation of paintings in the sense of understanding the deep structure of an art work requires an operational level of thought.

Machotka (1966) and Parsons (1976) have found age differences in the ability to analyze the surface and deep structure of paintings, and they explained these differences within a cognitive-developmental framework. Studying the reasons children gave for their preferences among paintings, Machotka found that children from 5 to 8 years of age based their preferences on subject matter and color, while children from ages 8 to 11 years based their preferences on formal qualities, such as realistic representation, contrast and harmony of colors, and clarity of presentation. Only at adolescence were style, composition, and perceived affect or expressive aspects of the painting cited as a basis for aesthetic preferences.

Machotka (1966) explained his results by relating the criteria used by the children as a basis for their preferences to Piaget's stages of cognitive development. He concluded that the ability to perceive the formal and affective dimensions of paintings is a function of operational thought.

Parsons (1976) distinguished four stages in the child's ability to analyze works of art, each stage based upon the cognitive level of the child. Children at Stage 1 (preoperational) are egocentric and prefer certain art works because of pleasing subject matter and colors. Children at Stage 2 (concrete operational) are starting to lose their egocentric view of the world, and they begin to evaluate art objects based upon more formal qualities, preferring paintings that are realistic and that are balanced and harmonious. Children enter Stage 3 (concrete operational) at preadolescence, when they begin to identify with the artist. Coherent with this move to identify with the artist is the view that art is an expression of emotion. At Stage 4 (formal operational), the expressive aspects of the work of art. increase in importance. Parsons concluded that the ability to perceive the formal and affective dimensions of art works increases with age and is a function of cognitive development.

Gardner (1970) measured awareness of formal and affective dimensions by investigating children's sensitivity to artistic style. He operationally defined sensitivity to style as the ability to identify paintings done by the same artist. In order to identify these paintings, a person must be able to perceive the qualities of line, texture, and composition that characterize a range of works done by the same artist and remain discernible regardless of the subject matter, dominant colors, or medium used.

Asking children to match paintings done by the same artist, Gardner (1970) found that when the subject matter was allowed to vary, the adolescents were able to identify the correct paintings significantly better than the younger children could. The younger children incorrectly matched paintings with similar content, while the older subjects could overlook the subject matter and base their selections on purely formal and/or affective similarities. But when the subject matter was held constant or was absent as in abstract paintings, children as young as 7 years could identify the correct paintings almost as well as the older subjects because they were forced to look for similarities in qualities other than content.

Based upon these findings, Gardner (1970) concluded that age differences in style sensitivity are not due to an inability to perceive the structural and expressive elements in paintings, but rather to the inability of younger children to decenter from the dominant element of subject matter. When children are forced to decenter from the subject matter, they can perceive the formal and affective elements in the painting and can utilize these elements to discriminate artistic style.

Instead of using preferential choices or sensitivity to artistic style, the present study measured children's awareness of the different dimensions of paintings by investigating their ability to analyze similarities and differences between paintings. This type of task provides more objective and exhaustive information about the subjects' ability to analyze paintings than does a task that asks subjects to make selections based on preferences. It also provides more specific information about the particular dimensions of paintings that the subjects can discriminate than does a task that asks subjects to match paintings done by the same artist.

\section{METHOD}

\section{Subjects}

Twenty-four subjects ranging from 7 years of age through high school and adults participated in the study. The children and adolescents were randomly selected from classes on field trips to the Philadelphia Museum of Art. The cognitive levels of the subjects were not directly assessed; however, age groups were formed to roughly approximate Piaget's preoperational, concrete operational, and formal operational periods. The eight subjects in the preoperational age group were 7 and 8 years of age; eight subjects from 9 to 12 years of age formed the concrete operational age group; and eight subjects 13 years of age and older were designated as the formal operational group.

\section{Procedure}

Each subject was shown five sets of three paintings (postcard prints), for a total of 15 paintings. Table 1 lists the paintings shown in each set. The paintings were chosen by the experimenters, with the aid of art experts, according to similarities in content, formal, and affective elements.

For each set, the subjects were asked to indicate which two of the three paintings they thought were the most similar to each other and why. The subjects were encouraged to give as many reasons for their initial selections as they could. The subjects were then asked in what ways, if any, the remaining two combinations of paintings in the set were similar. For example, if the subject initially selected Paintings 1 and 2 as being the most similar, he or she was then asked if there were any ways in which Paintings 2 and 3 and Paintings 1 and 3 were similar. The subjects were told that we were interested in the different ways people look at paintings and what dimensions different people focus on when asked to find similarities and differences in 
Table I

Artists and Titles of Paintings Used in the Five Sets

\begin{tabular}{|c|c|c|}
\hline & Artist & Title \\
\hline Set 1 & $\begin{array}{l}\text { Chagall } \\
\text { Sassetta } \\
\text { Delvaux }\end{array}$ & $\begin{array}{l}\text { Purim } \\
\text { Saint Anthony Leaving His Monastery } \\
\text { Trains du Soir }\end{array}$ \\
\hline Set 2 & $\begin{array}{l}\text { Seurat } \\
\text { Tissot } \\
\text { Villon }\end{array}$ & $\begin{array}{l}\text { Une Baignade, Asnieres } \\
\text { The Picnic } \\
\text { Between Toulouse and Albi }\end{array}$ \\
\hline Set 3 & $\begin{array}{l}\text { Vlaminck } \\
\text { Braque } \\
\text { Utrillo }\end{array}$ & $\begin{array}{l}\text { The Red Trees } \\
\text { Chrysanthemums } \\
\text { La Place du Tertre }\end{array}$ \\
\hline Set 4 & $\begin{array}{l}\text { Delaunay } \\
\text { Delaunay } \\
\text { Mondrian }\end{array}$ & $\begin{array}{l}\text { Windows Open Simultaneously } \\
\text { The City } \\
\text { Composition }\end{array}$ \\
\hline Set 5 & $\begin{array}{l}\text { Unknown } \\
\text { Braque } \\
\text { Picasso }\end{array}$ & $\begin{array}{l}\text { The Wilton Diptych } \\
\text { Still Life with Coffee Grinder } \\
\text { Les Demoiselles d'Avignon }\end{array}$ \\
\hline
\end{tabular}

paintings. This was done to relax the subjects and to make them feel more free to respond. The subjects' responses were taperecorded and classified into content, formal, and affective dimensions by four raters, according to the criteria previously mentioned. Interrater reliability was .80 .

Color was classified as either content or a formal element, depending on the quality of the response. Dondis (1976) treats color as a formal dimension. Instead of classifying color responses as formal, Machotka (1966) grouped color responses into a separate category. The raters in the present study classified color responses as content if the responses referred to specific colors that the paintings had in common. Color responses were classified as formal if they referred to the more abstract qualities of color, such as brightness, intensity, contrast, and tone.

The three paintings shown to the subjects in Set 5 are presented in Figure 1 as an example of the kinds of similarities that were mentioned by the subjects. Paintings 1 and 2 have similar colors; Paintings 1 and 3 have similar subject matter; and Paintings 2 and 3 have similar styles.

Subjects were shown two sets of paintings as practice trials before the experiment began. In these practice trials, the experimenter pointed out content, formal, and affective similarities among the paintings. This practice session, hopefully, gave the subjects an indication of the kinds of elements that could be used as a basis for their similarity judgments and encouraged the subjects to use more than one dimension in their analyses of the paintings.

Some subjects might have found it difficult to verbalize the reasons for their selections. To help eliminate this problem, the experimenters encouraged the subjects to point to particular elements in the painting if they were having difficulties expressing the reasons for their similarity judgments.

\section{RESULTS}

The independent variables in the study were painting dimensions, with three levels (content, formal, affective), and age, with three levels (Age Group 1: 7.8 years; Age Group 2: 9-12 years; Age Group 3: 13 years and older). Each subject received a single frequency score for each of the three dimensions. This score was obtained by averaging in each of the five sets the frequencies given by the four raters. These rater means were then averaged across the five sets. The number of responses that could be given by the subjects was unlimited, and older sub. jects in Age Groups 2 and 3 were found to give signifi- cantly more responses than the young Age Group 1 subjects $[F(2,21)=8.03, p<.01]$. To compensate for these differences in fluency, proportions of responses in each dimension were analyzed for the three age groups. Proportions partialled out the bias among the age groups due to fluency and enabled the experimenters to examine only the differences in type of responses made by the three age groups. The content and formal dimensions received the highest proportion of responses in all three age groups $[\mathrm{F}(2,42)=67.53$, $\mathrm{p}<.01]$. Very few affective responses were made by any of the subjects.

Comparing the age groups on each of the three dimensions, the youngest group made the most content responses and the least formal and affective, while the oldest group made the least content responses and the most formal and affective (see Figure 2). This Age by Dimension interaction was also significant $[\mathrm{F}(4,42)=2.72$, $p<.05]$.

\section{DISCUSSION}

Using an analysis of similarity judgments between paintings to study artistic perceptions, the present study supports previous findings of age differences in the ability to discriminate the content, formal, and affective dimensions inherent in paintings. Younger children centered on content in making similarity judgments. Older children and adults gave more reasons for their similarity judgments, mentioned a wider variety of dimensions as the bases for their judgments, and demonstrated
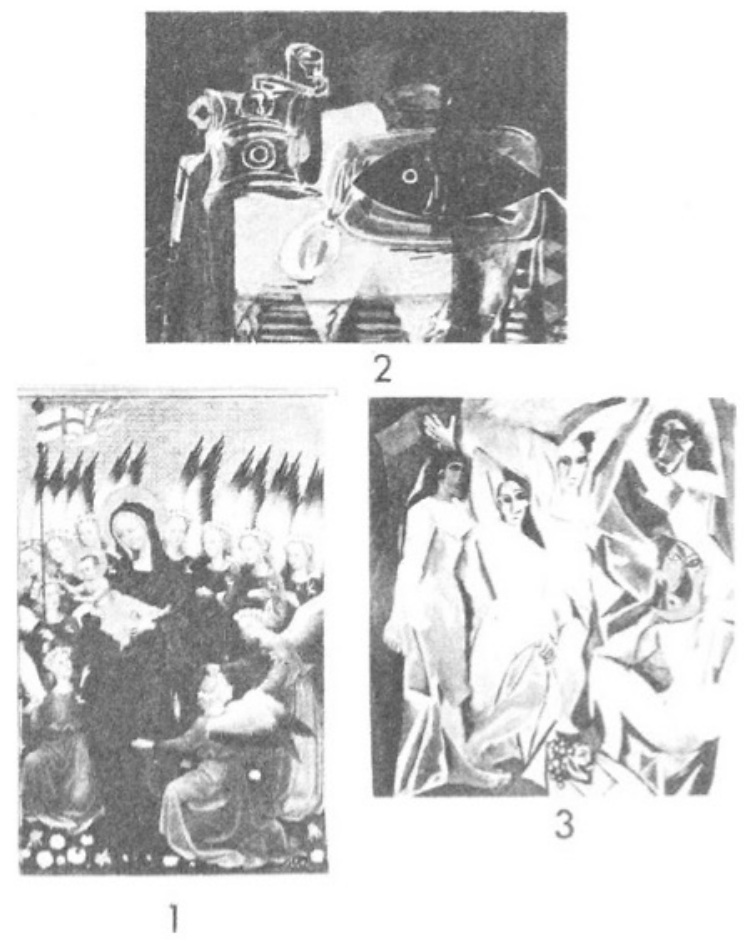

Figure 1. The three paintings in Set 5. Top (Painting 2), "Still Life with Coffee Grinder," by George Braque (private collection); lower left (Painting 1), "The Wilton Diptych," French school (National Gallery, London); lower right (Painting 3), "Les Demoiselles d'Avignon," by Picasso (Museum of Modern Art, New York). 


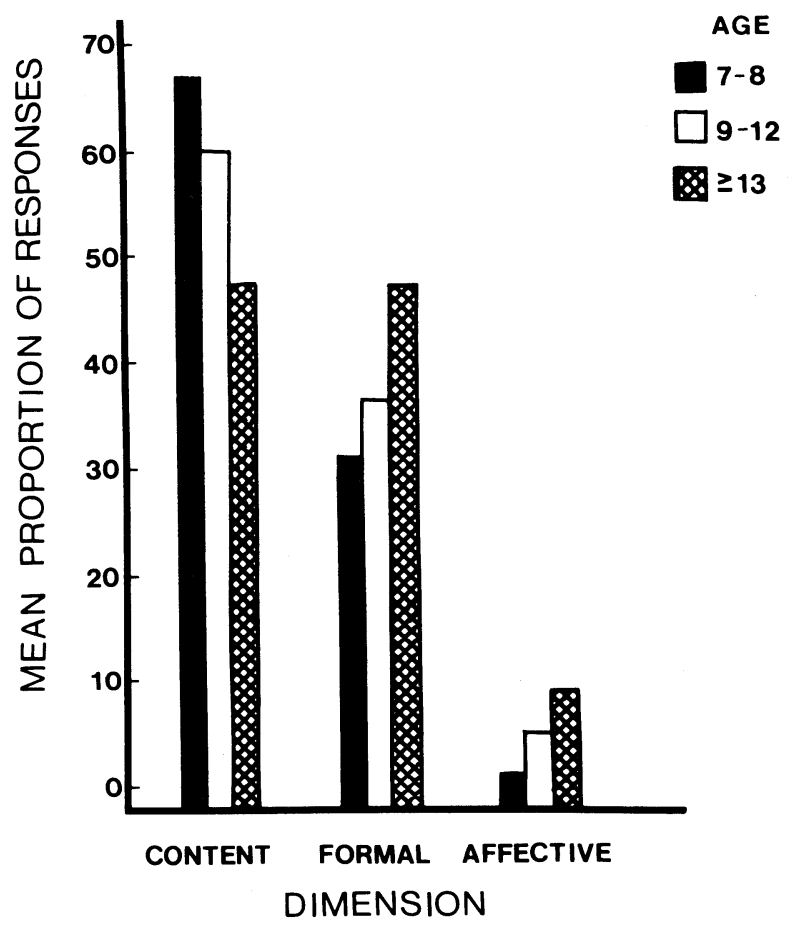

Figure 2. Mean proportions of content, formal, and affective responses for the three age groups.

deeper analytical ability than the younger children. This ability to analyze the deep structure of art works would thus seem to be related to attainment of operational thought. The adolescents and adults, however, did not use the affective dimension in making similarity judgments as often as was expected. Content was the most salient dimension for all three age groups. The lack of affective responses could have been due to an unwillingness to verbalize emotional reactions or to problems in interpretation and classification of responses by the raters. It could also indicate that awareness of formal and affective qualities involves artistic experience or training as well as operational thought.

Color was the most frequently mentioned reason for judging two paintings as similar for all three age groups. The formal use of color was not dependent upon age, contrary to expectations, since only $17 \%$ and $24 \%$ of the color responses given by the older children and adults in Age Groups 2 and 3, respectively, were abstract, as compared with $26 \%$ of the color responses given by the youngest children in Age Group 1. This could be due to the ambiguous nature of these responses, which made rating difficult. If the subjects had been asked to elaborate, the raters may have been better able to correctly classify the color responses into the content or formal category.

The presence of formal and affective dimensions in the similarity judgments of adolescents and adults and the almost total absence of these dimensions in the judgments of the youngest children support a cognitive-developmental theory of art appreciation. The preoperational children in Age Group 1 are not yet capable of understanding that paintings are expressions of the artist's ideas about reality because they have not yet attained a level of cognitive development that allows them to perform the necessary transformations from concrete representations to abstractions such as ideas, feelings, and experiences. The youngest children can analyze the surface structure or content of the painting, since the understanding that paintings are pictorial representations for physical objects and events is within the cognitive abilities of preoperational-aged children.

Experimental studies that investigate changes in children's sensitivity to the different dimensions of visual art and how these changes are related to cognitive development could provide art educators with valuable information about the development of aesthetic appreciation and could enable them to gear art education to level of cognitive ability so that children would be able to more fully understand and enjoy the artistic experience as either spectators or participants.

\section{REFERENCES}

Dondis, D. A primer of visual literacy. Cambridge, Mass: M.I.T. Press, 1976.

GaRDNER, H. Children's sensitivity to painting styles. Child Development, 1970, 41, 813-821.

Gibson, E. J. The development of perception as an adaptive process. American Scientist, 1970, 58, 98-107.

KNobler, N. The visual dialogue. New York: Holt, Rinehart, \& Winston, 1967.

MaсноткA, P. Aesthetic criteria in childhood: Justifications of preference. Child Development, 1966, 37, 877-885.

Parsons, M. A suggestion concerning the development of aesthetic experience in children. Journal of Aesthetics and Art Criticism, 1976, 34, 305-314.

(Received for publication October 22, 1979.) 